\title{
Selenium deficiency and the dynamics of changes of thyroid profile in patients with acute myocardial infarction and chronic heart failure
}

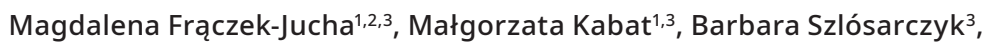 \\ Urszula Czubek ${ }^{3}$, Jadwiga Nessler ${ }^{1,3}$, Andrzej Gackowski ${ }^{1,3}$ \\ 1 Department of Coronary Disease and Heart Failure, Institute of Cardiology, Jagiellonian University Medical College, Kraków, Poland \\ 2 Department of Emergency Medical Care, Jagiellonian University Medical College, Kraków, Poland \\ 3 Department of Coronary Disease and Heart Failure, John Paul II Hospital, Kraków, Poland
}

\section{KEY WORDS}

heart failure,

myocardial infarction, selenium, thyroid hormones

EDITORIAL

page 657
Correspondence to:

Andrzej Gackowski, MD, PhD,

Department of Coronary

Disease and Heart Failure

John Paul II Hospital,

ul. Prądnicka 80, 31-202 Kraków,

Poland, phone: +48126142218 , email: agackowski@gmail.com Received: April 14, 2019. Revision accepted: May 6, 2019. Published online: May 7, 2019. Kardiol Pol. 2019; 77 (7-8): 674-682 doi:10.33963/KP.14822

Copyright by the Author(s), 2019

\section{ABSTRACT}

BACKGROUND Selenium (Se) is incorporated in 25 enzymes, for example, glutathione peroxidase (activated by oxidative stress) and deiodinases (converting thyroid hormones). Oxidative stress present in heart failure (HF) and myocardial infarction (MI) might cause Se deficiency and decreased thyroxine to triiodothyronine conversion.

AIMs We sought to evaluate Se levels in Polish patients with MI, $\mathrm{HF}$, and healthy volunteers in relation to thyroid hormone levels.

METHODS The study group consisted of 143 participants: 54 patients with MI, 59 patients with decompensated $\mathrm{HF}$, and 30 healthy matched volunteers. The patients underwent echocardiography and laboratory tests on admission and 5 months later.

RESULTS Selenium levels were lower in patients with MI and HF than in controls (median [interquartile range, IQR], 65.9 [55.2-76.1] $\mu \mathrm{g} / \mathrm{l}$ and 59.7 [47.7-70.7] $\mu \mathrm{g} / \mathrm{l}$ vs 93.2 [84.2-99.1] $\mu \mathrm{g} / \mathrm{l}$, respectively; $P<0.001)$. The Se deficiency was very common in patients with $\mathrm{MI}$ and $\mathrm{HF}$, while it was rare in controls $(70.37 \%$ and $74.58 \%$ vs $10 \%$, respectively; $P<0.001$ ). Patients with $\mathrm{MI}$ and $\mathrm{HF}$ presented lower free triiodothyronine $\left(\mathrm{FT}_{3}\right)$ levels and lower $\mathrm{FT}_{3}$ to free thyroxine $\left(\mathrm{FT}_{4}\right)$ ratio in comparison with controls (median [IQR], $3.90[3.60-4.38] \mathrm{pmol} / \mathrm{l}$ and $4.25[3.57-4.60] \mathrm{pmol} / \mathrm{l}$ vs $4.92[4.50-5.27] \mathrm{pmol} / \mathrm{l} ; P<0.001$; and 0.25 [0.23-0.29] and $0.25[0.21-0.28]$ vs $0.32[0.29-0.37] ; P<0.001$, respectively). There was a weak to moderate correlation between Se level, $\mathrm{FT}_{3}$ level, and the $\mathrm{FT}_{3} / \mathrm{FT}_{4}$ ratio. At follow-up, the $\mathrm{FT}_{3} / \mathrm{FT}_{4}$ ratio tended to normalize in patients with MI and remained decreased in patients with $\mathrm{HF}$ (mean [SD], 0.31 [0.06] vs 0.27 [0.05]; $P<0.001)$.

CONCLUSIONS Selenium deficiency is very common in Polish patients with MI and HF. Thyroid hormones disturbances were more transient in patients with MI, but more chronic in those with $\mathrm{HF}$.

INTRODUCTION Selenium (Se) is a micronutrient important for human health. It is incorporated as selenocysteine at the active site of 25 selenoproteins, for example, glutathione peroxidase (GPX), iodothyronine deiodinases, selenoprotein $\mathrm{P}$, thioredoxin reductase, selenoprotein $\mathrm{S}$, and other. Due to the U-shaped dose-response relationship, toxic concentrations of Se may be harmful, which is why only people with low Se levels may benefit from Se supplementation. Dietary Se intake varies worldwide from $7 \mu \mathrm{g}$ to $4990 \mu \mathrm{g}$ per day. The mean value in Europe is $40 \mu \mathrm{g}$ per day and in the United States, $93 \mu \mathrm{g}$ per day (in women) to $134 \mu \mathrm{g}$ per day (in men). Nutritional products that are rich in Se are Brazil nuts, offal, seafood, cereals, and grains. ${ }^{1-4}$

Oxidative stress caused by the insufficient antioxidant dietary intake and improper balance 


\section{WHAT'S NEW?}

The function of deiodinases (thyroid hormone converting enzymes) may be disturbed by oxidative stress accompanying heart failure (HF) or myocardial infarction (MI), because both deiodinases and glutathione peroxidase (an antioxidant enzyme) are selenoproteins competing for selenium (Se). Our research revealed that Se deficiency is very common in Polish patients with MI or HF. They also present with lower free triiodothyronine levels and lower free triiodothyronine to free thyroxine ratio. We noticed that thyroid hormones disturbances are transient in acute MI, but chronic in HF. There is a mild-to-moderate correlation between Se and thyroid hormone levels. Further studies are needed to investigate whether Se deficiency contributes to HF progression. They may provide the rationale to support Se supplementation in HF.

between prooxidant and antioxidant enzymes, leading to an excess of reactive oxygen species, may be associated with cardiovascular diseases. ${ }^{5}$ It has been proven that low GPX activity can be used to identify patients at high cardiovascular risk. ${ }^{6,7}$ As Se levels correlate positively with enzymatic activity and protein levels of GPX, Se plasma analysis may be used for an indirect assessment of oxidative stress. ${ }^{8,9} \mathrm{GPX}$ and Se deficiency may exacerbate endothelial dysfunction, low-density lipoprotein cholesterol oxidation, atherosclerosis, myocardial susceptibility to ischemia and reperfusion injury, as well as impaired thyroid hormone conversion. These phenomena may contribute to subsequent heart failure (HF). ${ }^{9-13}$

A prospective epidemiological study conducted in Finland revealed that the serum Se concentration was inversely related to the risk of myocardial infarction (MI) and cardiovascular death. ${ }^{14}$ Another study conducted in New Zealand showed that a decrease in blood level of Se in cigarette smokers is a risk factor for coronary heart disease. ${ }^{15}$ Se deficiency is mentioned in the current European Society of Cardiology guidelines for the diagnosis and treatment of acute and chronic HF as a nutritional cause of the disease. ${ }^{16}$ Se deficiency is a possible risk factor for Keshan disease, which is an endemic cardiomyopathy in Se-poor areas of China. ${ }^{17}$ Even in Se-rich areas, HF caused by Se deficiency may be a result of malnutrition occurring in patients with HIV, gastrointestinal diseases, parenteral nutrition or in those after bariatric surgery. ${ }^{18-20}$

Because selenoproteins (GPX and iodothyronine deiodinases) may compete for Se, oxidative stress causing Se deficiency may contribute to disturbances of thyroid hormone conversion. These conditions alone and collectively may affect the cardiovascular system. Lifestyle, diet, and smoking habits differ from country to country and may influence Se levels. To our knowledge, Se levels have not been studied in the context of thyroid function in patients with cardiovascular disease in Poland. The main purpose of our study was, therefore, to evaluate Se levels in
Polish patients with MI, HF, and healthy volunteers in relation to thyroid hormone levels. We also evaluated the clinical course of MI and HF in subgroups with normal or lowered Se levels.

METHODS Study population The protocol of this prospective cohort study was approved by the local ethics committee. All study procedures performed involving human participants were in accordance with the ethical standards of the Declaration of Helsinki. Between June 2015 and August 2017, we prospectively evaluated 113 consecutive inpatients and 30 healthy volunteers who expressed their written informed consent and met the inclusion/ exclusion criteria, which were as follows:

1 The MI group included patients with acute ST-segment elevation MI or non-ST-segment elevation MI, treated with primary percutaneous coronary intervention. ${ }^{21}$ The exclusion criteria were known HF, thyroid disease, treatment with amiodarone, glucocorticoids, or propranolol, as well as clinical evidence of severe systemic disease such as inflammatory, autoimmune, neoplastic, or chronic renal disease (estimated glomerular filtration rate $[\mathrm{eGFR}]<30 \mathrm{ml} / \mathrm{min} / 1.73 \mathrm{~m}^{2}$ ). 2 The HF group included patients with decompensated HF with reduced ejection fraction. ${ }^{16}$ The exclusion criteria were acute coronary syndrome, thyroid disease, treatment with amiodarone, glucocorticoids, or propranolol, as well as clinical evidence of severe systemic disease such as inflammatory, autoimmune, neoplastic, or chronic renal disease (eGFR $<30 \mathrm{ml} / \mathrm{min} / 1.73 \mathrm{~m}^{2}$ ).

3 The $C$ group (control group) included healthy volunteers with normal electrocardiogram matched for sex and age.

All patients with MI and $\mathrm{HF}$ received optimal guideline-directed medical treatment. ${ }^{16,21}$ Depending on the Se concentration, additional 4 subgroups were identified in the $\mathrm{MI}$ and $\mathrm{HF}$ groups: MI-A and HF-A subgroups including patients with Se concentration below the normal values and with $\mathrm{MI}$ or $\mathrm{HF}$, respectively, as well as MI-B and HF-B subgroups including patients without decreased Se levels and with MI or $\mathrm{HF}$, respectively.

Biochemical tests Single blood samples were collected for thyroid profiles and Se in the $C$ group. Serial blood samples were collected in MI and HF groups.

On the first and third day of hospitalization and at the follow-up visit, the patients had the following laboratory tests performed: thyroid stimulating hormone (TSH; electrochemiluminescence immunoassay [ECLIA] method), free thyroxine $\left(\mathrm{FT}_{4}\right)$, and free triiodothyronine ( $\mathrm{FT}_{3}$; ECLIA method). Then, the $\mathrm{FT}_{3} / \mathrm{FT}_{4}$ ratio was calculated. The reverse triiodothyronine 
TABLE 1 Characteristics of the whole group of patients with myocardial infarction and its subgroups according to selenium concentration

\begin{tabular}{|c|c|c|c|c|}
\hline Parameter & MI group $(n=54)$ & MI-A subgroup $(n=38$ ) & MI-B subgroup $(n=16)$ & $P$ value \\
\hline $\mathrm{Se}^{\mathrm{a}}, \mu \mathrm{g} / \mathrm{l}$ & $66.73(14.56)$ & $60.24(10.93)$ & $82.13(9.72)$ & $<0.001$ \\
\hline Age, y & $60.41(8.91)$ & $60.11(9.55)$ & $61.13(7.38)$ & 0.70 \\
\hline Male sex, n (\%) & $47(87.04)$ & $34(89.47)$ & $13(81.25)$ & 0.41 \\
\hline BMI, kg/m² & $26.2(24.8-30.8)$ & $26.7(24.4-30.6)$ & $26.2(24.8-32.3)$ & 0.76 \\
\hline STEMI, n (\%) & $41(75.93)$ & $27(71.05)$ & $14(87.50)$ & \multirow[t]{2}{*}{0.30} \\
\hline NSTEMI, n (\%) & $13(24.07)$ & $11(28.95)$ & $2(12.50)$ & \\
\hline hsTnT (max), ng/ml & $4.09(0.96-6.30)$ & $4.09(0.94-5.62)$ & $3.50(0.90-6.81)$ & 0.91 \\
\hline $\mathrm{TSH}^{\mathrm{b}}, \mu \mathrm{IU} / \mathrm{ml}$ & $1.12(0.72-1.59)$ & $1.11(0.74-1.54)$ & $1.13(0.64-1.72)$ & 0.87 \\
\hline $\mathrm{FT}_{3}{ }^{\mathrm{b}}, \mathrm{pmol} / \mathrm{l}$ & $4.21(3.86-4.71)$ & $4.30(3.90-4.82)$ & $3.90(3.77-4.38)$ & 0.21 \\
\hline $\mathrm{FT}_{4}^{\mathrm{b}}, \mathrm{pmol} / \mathrm{l}$ & $15.96(2.27)$ & $16.00(2.47)$ & $15.85(1.77)$ & 0.82 \\
\hline $\mathrm{FT}_{3} / \mathrm{FT}_{4}$ ratio & $0.26(0.24-0.30)$ & $0.26(0.23-0.30)$ & $0.26(0.24-0.30)$ & 0.73 \\
\hline $\mathrm{rT}_{3}{ }^{\mathrm{a}}, \mathrm{ng} / \mathrm{ml}$ & $0.20(0.13-0.28)$ & $0.22(0.14-0.28)$ & $0.18(0.12-0.21)$ & 0.14 \\
\hline NT-proBNPa, pg/ml & $809.0(385.5-1385.6)$ & $809.0(460.3-1489.5)$ & $667.5(106.5-1263.5)$ & 0.29 \\
\hline hs-CRPb, $\mathrm{mg} / \mathrm{l}$ & $6.98(3.17-12.38)$ & $6.68(2.40-11.88)$ & $7.86(4.97-13.65)$ & 0.35 \\
\hline$W B C^{b}, \times 10^{9} / l$ & $11.41(3.24)$ & $11.52(3.79)$ & $1.17(1.28)$ & 0.62 \\
\hline$W B C a, \times 10^{9} / 1$ & $8.87(2.35)$ & $9.36(2.41)$ & $7.69(1.73)$ & 0.02 \\
\hline eGFR, CKD-EPI ${ }^{b}$ & $78.06(16.72)$ & $79.61(17.32)$ & 74.38 (15.08) & 0.30 \\
\hline LVEDV, ml & $111.50(92.75-143.50)$ & $114.50(92.75-148.00)$ & $105.50(91.65-145.00)$ & 0.42 \\
\hline LVEF, \% & $52.63(10.31)$ & $52.08(11.12)$ & $53.94(8.27)$ & 0.55 \\
\hline
\end{tabular}

Data are presented as mean (SD) or median (interquartile range) unless indicated otherwise.

a Measured on the third day of hospitalization; b measured on the first day of hospitalization

Abbreviations: BMI, body mass index; eGFR, estimated glomerular filtration rate; $\mathrm{FT}_{3}$, free triiodothyronine; $\mathrm{FT}_{4}$, free thyroxine; hs-CRP, high-sensitivity C-reactive protein; hsTnT, high-sensitivity troponin T; LVEDV, left ventricular end-diastolic volume; LVEF, left ventricular ejection fraction; MI group, myocardial infarction group; NSTEMI, non-ST-segment elevation myocardial infarction; MI-A subgroup, myocardial infarction subgroup with Se below normal values; MI-B subgroup, myocardial infarction subgroup with normal Se values; NT-proBNP, N-terminal pro B-type Natriuretic Peptide; $\mathrm{rT}_{3}$, reverse triiodothyronine; Se, selenium; STEMI, ST-segment elevation myocardial infarction; TSH, thyroid stimulating hormone; WBC, white blood count

$\left(\mathrm{rT}_{3}\right)$ level was determined using the radioisotope method on the third day of hospitalization. Laboratory reference values for THS, $\mathrm{FT}_{3}, \mathrm{FT}_{4}$, and $\mathrm{rT}_{3}$ were $0.27-4.2 \mu \mathrm{IU} / \mathrm{ml}, 3.10$ $6.80 \mathrm{pmol} / 1,12.0-22.0 \mathrm{pmol} / \mathrm{l}$, and 0.09$0.35 \mathrm{ng} / \mathrm{ml}$, respectively.

The N-terminal pro-B-type natriuretic peptide (NT-proBNP) (ECLIA method) levels were determined on the first and third day of hospitalization and at the follow-up. The reference value for NT-proBNP was $<125.0 \mathrm{pg} / \mathrm{ml}$. The inflammatory markers, high-sensitivity $C$-reactive protein (hs-CRP) (immunoturbodimetric method) and white blood count (WBC) (hydrodynamic focusing method in flow cytometry), were determined on the first and third day of hospitalization. Creatinine levels (Jaffé Gen. 2 method, rate blanked, compensated) and eGFR using the CKD-EPI formula were assessed at admission.

In MI group, serum levels of high sensitivity troponin $\mathrm{T}$ (hsTnT), creatinine kinase MB (CK-MB), and creatinine kinase (CK) (ECLIA method) were measured at admission and repeated every
6 hours during the first 24 hours. Normal values of hsTnT, CK-MB and CK were $<0.014 \mathrm{ng} / \mathrm{ml}$, 0-24 U/l, and 0-190 U/l, respectively.

Biochemical tests were performed using the Roche Diagnostics GmbH (Mannheim, Germany) kits. Full blood count was performed using the Sysmex Corporation (Kobe, Japan) kits.

Blood samples for Se serum assays were taken on the third day of hospitalization. After collection, blood samples were left to clot for $30 \mathrm{~min}$ utes and were centrifuged afterwards (1300G, 12 minutes). Serum samples were frozen at $-80^{\circ} \mathrm{C}$ $\left(-112^{\circ} \mathrm{F}\right)$. On the day of analysis, samples were centrifuged (5000G, 5 minutes). Inductively coupled plasma mass spectrometry was used in the analyses. Se determination was performed on an inductively coupled plasma mass spectrometer NexION 350D (PerkinElmer, Shelton, Connecticut, United States). The spectrometer was equipped with a dynamic reaction cell operating with high purity methane. It was calibrated using an external calibration technique. Calibration standards were prepared from $10 \mu \mathrm{g} /$ 
TABLE 2 Characteristics of the whole group of patients with heart failure and its subgroups according to selenium concentration

\begin{tabular}{|c|c|c|c|c|}
\hline Parameter & HF group $(n=59)$ & HF-A group $(n=44)$ & HF-B group $(n=15)$ & $P$ value \\
\hline $\mathrm{Se}^{\mathrm{a}}, \mu \mathrm{g} / \mathrm{l}$ & $59.74(47.73-70.66)$ & $52.17(45.01-60.43)$ & $81.08(74.85-86.80)$ & $<0.001$ \\
\hline Age, y & $65.0(59.0-74.0)$ & $64.0(56.25-73.25)$ & $67.00(62.0-77.0)$ & 0.19 \\
\hline Male sex, n (\%) & $48(81.36)$ & $38(86.36)$ & $10(66.67)$ & 0.13 \\
\hline BMI, $\mathrm{kg} / \mathrm{m}^{2}$ & $28.4(25.5-32.3)$ & $28.9(25.6-33.3)$ & $28.1(24.9-31.0)$ & 0.35 \\
\hline $\mathrm{TSH}^{\mathrm{b}}, \mu \mathrm{IU} / \mathrm{ml}$ & $1.54(0.93-2.05)$ & $1.52(0.91-2.16)$ & $1.56(1.06-2.01)$ & 0.90 \\
\hline $\mathrm{FT}_{3}{ }^{\mathrm{b}}, \mathrm{pmol} / \mathrm{l}$ & $4.16(0.94)$ & $4.05(0.89)$ & $4.51(1.01)$ & 0.10 \\
\hline $\mathrm{FT}_{4}{ }^{\mathrm{b}}, \mathrm{pmol} / \mathrm{l}$ & $17.95(2.98)$ & $17.70(2.77)$ & $18.66(3.53)$ & 0.29 \\
\hline $\mathrm{FT}_{3} / \mathrm{FT}_{4}$ ratio ${ }^{\mathrm{b}}$ & $0.24(0.06)$ & $0.23(0.06)$ & $0.24(0.06)$ & 0.49 \\
\hline $\mathrm{rT}_{3}{ }^{\mathrm{a}}, \mathrm{ng} / \mathrm{ml}$ & $0.21(0.09)$ & $0.23(0.09)$ & $0.17(0.08)$ & 0.03 \\
\hline NT-proBNPb, pg/ml & 3478.0 (1888-6837) & $2989.5(1870-7011)$ & $4029.0(1909-5922)$ & 0.88 \\
\hline hs-CRPb ${ }^{2}$ mg/l & $4.77(1.90-9.83)$ & $6.73(1.93-10.29)$ & $2.75(1.62-7.10)$ & 0.20 \\
\hline WBC,$\times 10^{9} / l$ & $7.81(6.05-9.45)$ & $8.02(6.01-9.41)$ & $7.40(6.32-9.45)$ & 0.99 \\
\hline eGFR, CKD-EPI ${ }^{\mathrm{b}}$ & $65.90(18.92)$ & $64.40(17.73)$ & $70.20(22.06)$ & 0.31 \\
\hline LVEDV, ml & $234.47(86.11)$ & $230.43(81.77)$ & 246.33 (99.93) & 0.54 \\
\hline LVEF, \% & $23.96(7.92)$ & $24.36(8.00)$ & $22.80(7.81)$ & 0.51 \\
\hline $\begin{array}{l}\text { Number of patients with } \\
\text { restrictive mitral filling } \\
\text { patternc, } n(\%)\end{array}$ & $18^{d}(52.94)$ & $15^{e}(65.22)$ & $3^{f}(27.27)$ & 0.04 \\
\hline
\end{tabular}

Data are presented as mean (SD) or median (interquartile range) unless indicated otherwise.

a Measured on the third day of hospitalization; b measured on the first day of hospitalization; c patients with atrial fibrillation were excluded from this analysis; d $n=34 ;$ e $n=23 ;$ f $n=11$

Abbreviations: HF group, heart failure group; HF-A subgroup, heart failure subgroup with Se below normal values; HF-B subgroup, heart failure subgroup with normal Se values; others, see TABLE 1

ml Multielement Calibration Standard 3. Correlation coefficients for calibration curves were always greater than 0.999 . The analysis protocol assumed 100-fold dilution of serum in a reagent blank. The reagent blank consisted of $10 \mathrm{ml}$ of 65\% Suprapur Grade (Merck, Darmstadt, Germany) nitric acid, $0.20 \mathrm{ml}$ of Triton X-100 (PerkinElmer) filled to the mark of a 1 liter flask with class I deionized water (Merck Millipore). Germanium isotope, $\mathrm{Ge}^{74}$, was set as an internal standard.

The quality of Se determination was verified with the use of reference material Clincheck Plasmonorm Serum Trace Elements Level 1 (RECIPE Chemicals + Instruments $\mathrm{GmbH}$, Munich, Germany). Se reference levels were established in the group of 2500 women and 1600 men from the Polish population. The following reference values of Se levels were used by the local laboratory: 75.0-85.0 $\mu \mathrm{g} / \mathrm{l}$ and $65.0-$ $75.0 \mathrm{\mu g} / \mathrm{l}$ for women younger than 50 and older than 50 years of age, respectively; 85.0-95.0 $\mu \mathrm{g} / \mathrm{l}$ and $70.0-90.0 \mu \mathrm{g} / \mathrm{l}$ for men younger than 60 and older than 60 years of age, respectively.

Echocardiographic assessment Atransthoracic echocardiographic evaluation of the left ventricle was performed during hospitalization and at follow-up (Philips IE33, Amsterdam, the Netherlands) by the same echocardiographer with a blind review and confirmation by another echocardiographer. The following parameters were analyzed: left ventricular end-diastolic diameter and volume, left ventricular ejection fraction (LVEF), left ventricular filling profile, E/E' index, tricuspid annular plane systolic excursion, and right ventricular systolic pressure.

Study endpoints Major adverse cardiovascular events in the MI and HF groups included resuscitated cardiac arrest, cardiovascular death, rehospitalization for $\mathrm{HF}$ decompensation requiring intravenous diuretics and/or catecholamines, evidence of ventricular tachycardia, severe sinus bradycardia, or atrioventricular blocks.

Each event was analyzed during the hospital stay and during the follow-up of median (IQR) 154.0 (132.8-168.8) and 144.0 (123.0-161.0) days in the MI and HF group, respectively. The composite endpoint of the above adverse events was also analyzed.

Statistical analysis Categorical variables were presented as numbers and percentages. Continuous variables were expressed as mean (SD) or median and interquartile ranges 
TABLE 3 Comparison of patients with myocardial infarction, heart failure, and control group

\begin{tabular}{|c|c|c|c|c|c|}
\hline \multicolumn{2}{|l|}{ Characteristics } & MI group $(n=54)$ & HF group $(n=59)$ & $C$ group $(n=30)$ & $P$ value \\
\hline \multicolumn{2}{|l|}{ Age, y } & $61.0(53.8-67.3)$ & $65.0(59.0-74.0)$ & $61.5(57.5-68.8)$ & 0.08 \\
\hline \multicolumn{2}{|l|}{ Male sex, n (\%) } & 47 (87.04) & $48(81.36)$ & $25(83.33)$ & 0.71 \\
\hline \multicolumn{2}{|l|}{ Smoking, n (\%) } & $33(61.11)$ & $21(35.59)$ & $8(27.59)$ & $0.004^{a, b}$ \\
\hline \multicolumn{2}{|l|}{$\mathrm{BMI}, \mathrm{kg} / \mathrm{m}^{2}$} & $26.2(24.8-30.79)$ & $28.4(25.5-32.3)$ & $30.1(27.4-34.8)$ & $0.01^{b}$ \\
\hline \multicolumn{2}{|l|}{$\mathrm{SBP}, \mathrm{mm} \mathrm{Hg}$} & $153.0(137.0-167.3)$ & $123(111-138)$ & $140.5(123-155)$ & $<0.001^{\mathrm{a}, \mathrm{c}}$ \\
\hline \multicolumn{2}{|l|}{$\mathrm{DBP}, \mathrm{mm} \mathrm{Hg}$} & $91.9(13.1)$ & $80.8(15.0)$ & $84.1(13.3)$ & $<0.001^{\mathrm{a}, \mathrm{b}}$ \\
\hline \multicolumn{2}{|l|}{$\mathrm{Se}, \mu \mathrm{g} / \mathrm{l}$} & $65.9(55.2-76.1)$ & $59.7(47.7-70.6)$ & $93.2(84.2-99.1)$ & $<0.001^{b, c}$ \\
\hline \multicolumn{2}{|l|}{ Se deficiency, n (\%) } & $38(70.37)$ & $44(74.58)$ & $3(10.00)$ & $<0.001^{b, c}$ \\
\hline \multirow[t]{4}{*}{ First day of hospitalization } & $\mathrm{TSH}, \mu \mathrm{IU} / \mathrm{ml}$ & $1.12(0.72-1.59)$ & $1.54(0.93-2.05)$ & $1.08(0.68-1.80)$ & $0.01^{a, c}$ \\
\hline & $\mathrm{FT}_{3}, \mathrm{pmol} / \mathrm{l}$ & $4.21(0.69)$ & $4.16(0.94)$ & $4.99(0.66)$ & $<0.001^{b, c}$ \\
\hline & $\mathrm{FT}_{4}, \mathrm{pmol} / \mathrm{l}$ & $15.96(2.27)$ & $17.95(2.98)$ & $15.31(1.91)$ & $<0.001^{\mathrm{a}, \mathrm{c}}$ \\
\hline & $\mathrm{FT}_{3} / \mathrm{FT}_{4}$ ratio & $0.27(0.04)$ & $0.24(0.06)$ & $0.33(0.05)$ & $<0.001^{a, b, c}$ \\
\hline \multirow[t]{4}{*}{ Third day of hospitalization } & $\mathrm{TSH}, \mu \mathrm{IU} / \mathrm{ml}$ & $2.23(1.20-3.11)$ & $1.60(1.16-2.03)$ & $1.08(0.68-1.80)$ & $<0.001^{b, c}$ \\
\hline & $\mathrm{FT}_{3}, \mathrm{pmol} / \mathrm{l}$ & $3.90(3.60-4.38)$ & $4.25(3.57-4.60)$ & $4.92(4.50-5.27)$ & $<0.001^{b, c}$ \\
\hline & $\mathrm{FT}_{4}, \mathrm{pmol} / \mathrm{l}$ & $5.33(2.07)$ & $17.40(2.57)$ & $15.31(1.91)$ & $<0.001^{\mathrm{a}, \mathrm{c}}$ \\
\hline & $\mathrm{FT}_{3} / \mathrm{FT}_{4}$ ratio & $0.25(0.23-0.29)$ & $0.25(0.21-0.28)$ & $0.32(0.29-0.37)$ & $<0.001^{b, c}$ \\
\hline \multirow[t]{4}{*}{ Follow-up } & $\mathrm{TSH}, \mu \mathrm{IU} / \mathrm{ml}$ & $1.21(0.95-1.66)$ & $1.48(1.08-2.10)$ & $1.08(0.68-1.80)$ & 0.047 \\
\hline & $\mathrm{FT}_{3}, \mathrm{pmol} / \mathrm{l}$ & $4.99(4.50-5.28)$ & $4.66(4.10-4.96)$ & $4.92(4.50-5.27)$ & 0.03 \\
\hline & $\mathrm{FT}_{4}, \mathrm{pmol} / \mathrm{l}$ & $16.35(2.60)$ & $17.41(2.66)$ & $15.31(1.91)$ & $0.002^{c}$ \\
\hline & $\mathrm{FT}_{3} / \mathrm{FT}_{4}$ ratio & $0.31(0.06)$ & $0.27(0.05)$ & $0.33(0.05)$ & $<0.001^{\mathrm{a}, \mathrm{c}}$ \\
\hline \multicolumn{2}{|l|}{ Prevalence of low $\mathrm{T}_{3}, \mathrm{n}(\%)$} & $7(12.96)$ & $9(15.25)$ & $0(0.00)$ & 0.08 \\
\hline
\end{tabular}

Data are presented as mean (SD) or median (interquartile range) unless indicated otherwise.

a $P<0.05 \mathrm{MI}$ group vs HF group; b $P<0.05 \mathrm{MI}$ group vs $C$ group; $\quad \mathrm{c} \quad P<0.05 \mathrm{HF}$ group vs $C$ group

Abbreviations: DBP, diastolic blood pressure; SBP, systolic blood pressure; others, see TABLE1

(IQR). The normality of distribution was assessed using the Shapiro-Wilk test. The equality of variances was assessed using the Levene test. The between-group differences were determined using the $t$ test or Welch $t$ test depending on the equality of variances for normally distributed variables. The Mann-Whitney test was used for nonnormally distributed continuous variables. Categorical variables were compared using the Pearson $\mathrm{X}^{2}$ test or the Fisher exact test if $20 \%$ of cells had an expected count of less than 5 . For 2 paired data samples, the 2-tailed $t$ test was used if differences between pairs were normally distributed, and the Wilcoxon signed-rank if they were not normally distributed. For more than 2 measurements, the repeated measures ANOVA was used. Post hoc analyses were made using the Tukey-Kramer HSD for independent samples or the Steel-Dwass method, for paired samples. The $P$ values were adjusted using the Bonferroni correction. The correlations between the variables were determined using the Pearson's correlation coefficient or Spearman rank correlation coefficient, depending on normality. The statistical analyses were performed with JMP ${ }^{\circledR}$ version 14.0 .0 software (SAS Institute INC., Cary, North Carolina, United States) and $R$ version 3.4.1 software ( $R$ Core Team. $R$ : A language and environment for statistical computing. R Foundation for Statistical Computing. Vienna, Austria, 2017). A P value of less than 0.05 was considered significant.

RESULTS The characteristics of the MI and HF groups as well as subgroups identified based on Se concentration are presented in TABLE1 and TABLE2.

There was no difference in age, sex, body mass index (BMI), MI type, culprit coronary artery, as well as prevalence of hypertension, diabetes mellitus, dyslipidemia, and smoking between the MI-A and MI-B subgroups. Furthermore, subgroups did not differ with regards to the following laboratory tests: hsTnT, CK-MB, CK, NT-proBNP, hs-CRP, eGFR, TSH, thyroid hormones, and all analyzed echocardiographic parameters. 


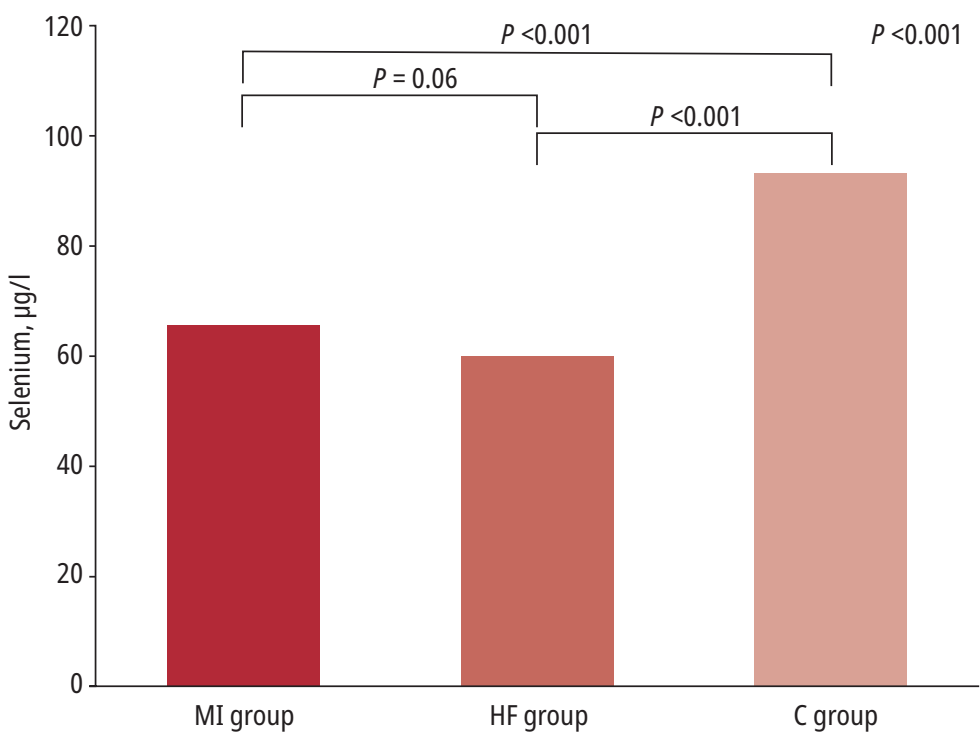

FIGURE 1 Selenium plasma levels in patients with myocardial infarction, heart failure, and in controls. For medians (interquartile ranges), see TABLE3. Abbreviations: See TABLE 1
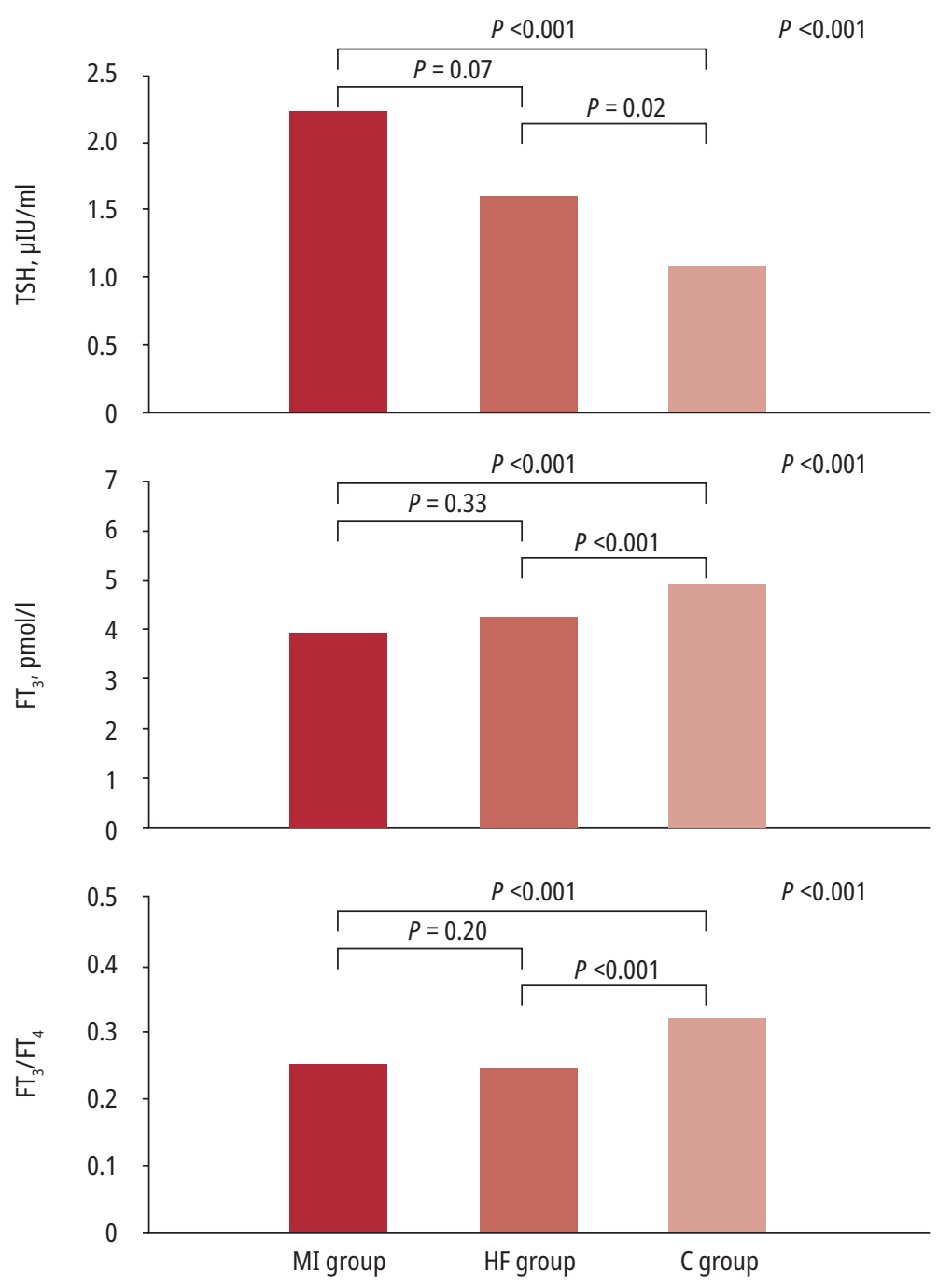

FIGURE 2 Thyroid stimulating hormone levels, free triiodothyronine levels, and free triiodothyronine to free thyroxine ratio measured on the third day of hospitalization in patients with myocardial infarction and heart failure in comparison with controls. For medians (interquartile ranges), see TABLE3. Abbreviations: See TABLE 1
However, the patients in the MI-A subgroup had a significantly higher WBC count on the third day of hospitalization as compared with patients from the MI-B subgroup.

We demonstrated that patients from the HF-A subgroup presented with higher $\mathrm{rT}_{3}$ levels and more often had a restrictive mitral filling pattern in comparison with patients from the HF-B subgroup. There was no difference in age, sex, BMI, prevalence of hypertension, diabetes mellitus, dyslipidemia, smoking, and HF etiology between the HF-A and HF-B subgroups. Similarly, there was no difference in the NT-proBNP, hs-CRP, WBC, eGFR, TSH, $\mathrm{FT}_{3}, \mathrm{FT}_{4}$, levels, $\mathrm{FT}_{3} / \mathrm{FT}_{4}$ ratio and the echocardiographic parameters between the HF-A and HF-B subgroups.

There was no difference in the incidence of any individual major adverse cardiovascular event ( $P>0.05$ for each predefined endpoint) or in the composite endpoint of all adverse events ( $P>0.05$ ) between MI-A and HF-A subgroups in comparison with MI-B and HF-B subgroups.

The comparison of $\mathrm{MI}, \mathrm{HF}$, and $\mathrm{C}$ groups is presented in TABLE3. There were no differences in age and sex between groups. The studied groups differed with respect to BMI and blood pressure. The Se deficiency was found in the majority of participants from MI and HF groups, but only the minority of participants in the control group. Furthermore, the Se levels were lower in both MI and HF groups in comparison with the controls (TABLE3, FIGURE 1).

The between-group differences were shown in the $\mathrm{TSH}, \mathrm{FT}_{3}$, and $\mathrm{FT}_{4}$ levels as well as the $\mathrm{FT}_{3}$ / $\mathrm{FT}_{4}$ ratio (table3, FiguRE2). There were within-group differences in $\mathrm{FT}_{3}$ levels and $\mathrm{FT}_{3} / \mathrm{FT}_{4}$ ratio changes in both MI and HF groups (FIGURE3). There was also a dynamic change of TSH concentration during the acute phase of MI and its normalization during follow-up (FIGURE3).

Correlation analysis including $\mathrm{Se}, \mathrm{TSH}$, and $\mathrm{TH}$ levels is presented in table 4 and FIgURE 4 . There were weak correlations between $\mathrm{Se}, \mathrm{FT}_{3}$, and $\mathrm{FT}_{4}$. Moderate correlations were found between $\mathrm{Se}$ and $\mathrm{FT}_{3} / \mathrm{FT}_{4}$ ratio. There was no correlation between $S e$ and other clinical variables including LVEF, hsT, CK, CKMB, NT-proBNP, creatinine, WBC, or hs-CRP.

DISCUSSION Our study showed that Se levels were lower in both patients with MI and chronic HF in comparison with healthy controls. Previously published research yielded inconclusive results. De Lorgeril et $\mathrm{al}^{22} \mathrm{dem}$ onstrated low dietary intake and blood Se levels in French patients with chronic HF. Similarly, Kosar et al ${ }^{23}$ from Turkey demonstrated that both dilated idiopathic and ischemic cardiomyopathy were associated with lower Se levels. Conversely, the study by Ghaemian et $\mathrm{al}^{24}$ carried out in Northern Iran did not support 

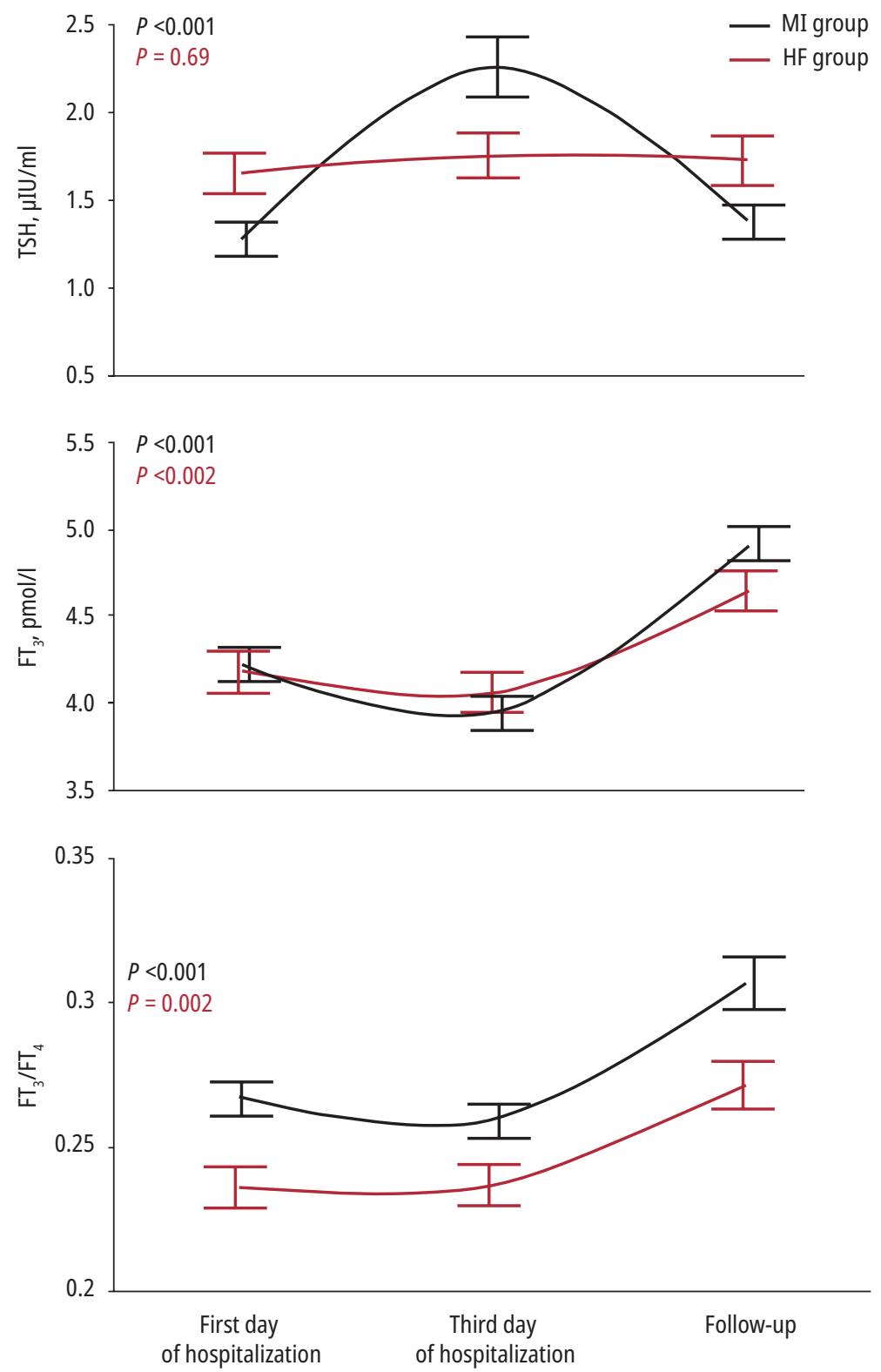

FIGURE 3 Changes of thyroid stimulating hormone and free triiodothyronine levels, and free triiodothyronine to free thyroxine ratio over time in patients with myocardial infarction and heart failure; for means (SD) or medians (interquartile ranges), see TABLE 3. Abbreviations: see TABLE 1

TABLE 4 Correlations between the levels of selenium, thyroid-stimulating hormone, and thyroid hormones

\begin{tabular}{llll} 
Variable & By variable & Correlation & P value \\
Se & $\mathrm{TSH}$ & -0.1427 & 0.09 \\
\hline $\mathrm{Se}$ & $\mathrm{FT}_{3}$ & 0.3900 & $<0.001$ \\
\hline $\mathrm{Se}$ & $\mathrm{FT}_{4}$ & -0.2136 & 0.01 \\
\hline $\mathrm{Se}$ & $\mathrm{FT}_{3} / \mathrm{FT}_{4}$ & 0.4294 & $<0.001$ \\
\hline
\end{tabular}

Abbreviations: see TABLE 1

these results. ${ }^{24}$ Lower Se concentrations were previously found in patients with myocardial infarction..$^{15,25-27}$ Discrepancies found in various studies might have been caused by differences in Se intake in distinctive geographical areas. The Mediterranean diet in Northern Iran is rich in Se, which may explain high Se levels found in both HF patients and healthy controls in the discussed study. ${ }^{22,24}$

We did not find correlations between Se and clinical variables reflecting disease severity in the present study. Previously, Se levels were found to be positively correlated with serum $\mathrm{CK}$ activity, serum myoglobin, and maximum troponin levels. ${ }^{25,28,29}$ Another study revealed that Se may play a role in the clinical severity of HF (assessed by peak exercise oxygen consumption), ${ }^{22}$ rather than in the degree of left ventricular dysfunction. ${ }^{22-24}$ However, the results are inconclusive because some previous studies found a positive correlation between Se levels and LVEF in $\mathrm{HF}$, and coronary artery disease. ${ }^{30-32,28}$ Nevertheless, sample sizes of the above study groups were very limited.

The presented findings suggest that Se levels may be lowered in both acute and chronic cardiac disorders. Further studies are needed as it is not clear whether the Se deficiency contributes to disease progression or is merely a marker of its severity. Furthermore, the data on Se supplementation and its possible positive effect on clinical variables is very limited and not focused on Se alone, as multiple micronutrients taken together were studied instead. It is also important that in studies of Se supplementation, baseline and target Se levels were not clearly defined, despite a known possibly harmful effect of Se overdose. ${ }^{33-35}$

There is growing evidence that oxidative stress and thyroid function are significant factors in HF development, while GPX levels correlate with Se concentrations. We sought to check the relationship between the Se and thyroid hormone levels and only found a weak correlation; however, a moderate correlation between Se level and $\mathrm{FT}_{3} / \mathrm{FT}_{4}$ ratio was found. It would be of interest to investigate the causality of this relationship.

Our results showed between-group differences in thyroid profiles. Patients with MI and $\mathrm{HF}$ presented with lower $\mathrm{FT}_{3}$ levels in comparison with the controls. Patients with MI presented with dynamic TSH and $\mathrm{FT}_{3}$ changes over the first 3 days of hospitalization. Similar findings were reported by Friberg et $\mathrm{al}^{36}$ who demonstrated a rapid down-regulation of thyroid hormones in acute MI.

Low $\mathrm{T}_{3}$ syndrome and a decreased $\mathrm{FT}_{3} / \mathrm{FT}_{4}$ ratio were previously shown to be prognostic predictors of death in patients with heart diseases. ${ }^{37,38}$ Our data indicates a difference in $\mathrm{T}_{4}$ to $\mathrm{T}_{3}$ conversion between acute and chronic conditions. Furthermore, whereas there was no difference in the $\mathrm{FT}_{3} / \mathrm{FT}_{4}$ ratio between the $\mathrm{MI}$ and control groups at follow-up, the HF group had a lower $\mathrm{FT}_{3} / \mathrm{FT}_{4}$ ratio than the control group. These findings suggest that changes of the $\mathrm{FT}_{3} / \mathrm{FT}_{4}$ ratio 


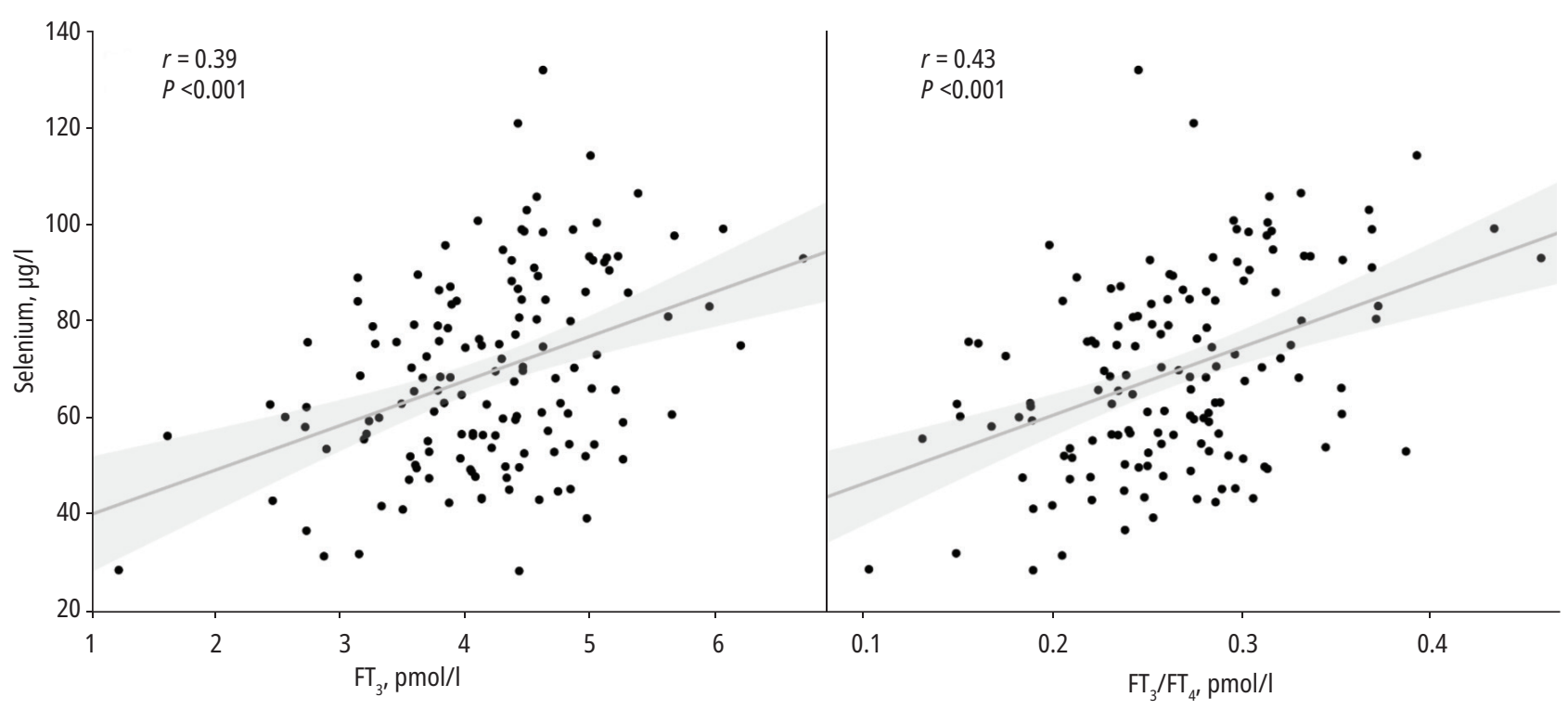

FIGURE 4 Correlation between the levels of selenium, free triiodothyronine, and free triiodothyronine to free thyroxine ratio, measured on the third day of hospitalization Abbreviations: See TABLE 1

are more dynamic and transient in MI than in HF, which is a chronic condition.

Although we were able to find articles on Se deficiency and thyroid hormone disturbances in HF and MI patients, there are no studies involving both conditions together. Lima et $\mathrm{al}^{39}$ did not find a correlation between Se and thyroid hormone levels in HF and concluded that there is a possible link between hypothyroidism, but not micronutrient levels, and the severity of HF. However, in our research not only did we demonstrate lower Se levels and thyroid hormones disturbances in study groups, but we also found a correlation between them. Perhaps there is a relationship between these phenomena. In our opinion, further research focused on Se levels, Se-dependent enzymes, and their influence on the course of cardiovascular diseases, especially HF, is needed.

In conclusion, Se levels in patients with both acute MI and HF are lower than in healthy volunteers. The Se deficiency is highly prevalent in acute MI as well as both acute and chronic HF. The correlation between Se and thyroid hormone levels was found to be weak to moderate.

Further research on Se deficiency in relation to oxidative stress markers and thyroid hormone conversion disturbances in patients with cardiovascular diseases, particularly HF, is needed. The potential role of Se deficiency in HF progression should also be studied to verify whether there are possible benefits of Se supplementation in these patients.

Study limitations Patient enrolment and conducting the research of decompensated HF or acute MI with strict entry criteria are difficult. As a result, the sample size was limited.
We mainly sought to evaluate the Se and thyroid status in both groups and compare it to that of controls. The study sample was not calculated to enable an analysis of hard endpoints, therefore the value of clinical event rate assessment is limited. The control group was selected so as to have similar demographic characteristics as the study groups; however, the BMI median in the control group was above the normal range, which is a disadvantage of our research. The study was intended to show a real-life group of patients with HF and MI, which is why we did not exclude smokers, although smoking may influence the Se levels. For the same reason we did not exclude smokers from the control group to ensure the groups were comparable.

\section{ARTICLE INFORMATION}

ACKNOWLEDGMENTS This work was supported by Jagiellonian University Medical College statutory funds (grant number K/ZDS/005640; to AG).

\section{CONFLICT OF INTEREST None declared.}

OPEN ACCESS This is an Open Access article distributed under the terms of the Creative Commons Attribution-NonCommercial-NoDerivatives 4.0 International License (CC BY-NC-ND 4.0), allowing third parties to download articles and share them with others, provided the original work is properly cited, not changed in any way, distributed under the same license, and used for noncommercial purposes only. For commercial use, please contact the journal office at kardiologiapolska@ptkardio.pl.

HOW TO CITE Frączek-Jucha M, Kabat M, Szlósarczyk B, et al. Selenium deficiency and the dynamics of changes of thyroid profile in patients with acute myocardial infarction and chronic heart failure. Kardiol Pol. 2019; 77: 674-682. doi:10.33963/KP.14822

\section{REFERENCES}

1 Rayman MP. Selenium and human health. Lancet. 2012; 379: 1256-1268.

2 Benstoem C, Goetzenich A, Kraemer S, et al. Selenium and its supplementation in cardiovascular disease-what do we know? Nutrients. 2015; 7: 3094-3118.

3 Joseph J, Loscalzo J. Selenistasis: epistatic effects of selenium on cardiovascular phenotype. Nutrients. 2013; 5: 340-358.

4 Köhrle J, Jakob F, Contempré B, et. al. Selenium, the thyroid, and the endocrine system. Endocr Rev. 2005; 26: 944-984.

5 Pignatelli P, Menichelli D, Pastori D, et al. Oxidative stress and cardiovascular disease: new insights. Kardiol Pol. 2018; 76: 713-722. 
6 Schnabel R, Lackner KJ, Rupprecht HJ, et al. Glutathione peroxidase-1 and homocysteine for cardiovascular risk prediction: results from the AtheroGene study. J Am Coll Cardiol. 2005; 45: 1631-1617.

7 Espinola-Klein C, Rupprecht HJ, Bickel C, et al; AtheroGene Investigators. Glutathione peroxidase-1 activity, atherosclerotic burden, and cardiovascular prognosis. Am J Cardiol. 2007; 99: 808-812.

8 Takahashi K, Newburger PE, Cohen HJ. Glutathione peroxidase protein. Absence in selenium deficiency states and correlation with enzymatic activity. J Clin Invest. 1986; 77: 1402-1404.

9 de Lorgeril M, Salen P. Selenium and antioxidant defenses as major mediators in the development of chronic heart failure. Heart Fail Rev. 2006; 11: 13-17.

10 Tanguy S, Toufektsian MC, Besse S, et al. Dietary selenium intake affects cardiac susceptibility to ischaemia/reperfusion in male senescent rats. Age Ageing. 2003; 32: 273-278.

11 Toufektsian MC, Boucher F, Pucheu S, et al. Effects of selenium deficiency on the response of cardiac tissue to ischemia and reperfusion. Toxicology. 2000; 148: 125-132.

12 Dallak M. A synergistic protective effect of selenium and taurine against experimentally induced myocardial infarction in rats. Arch Physiol Biochem. 2017; 123: $344-355$.

13 Venardos KM, Perkins A, Headrick J, et al. Myocardial ischemia-reperfusion injury, antioxidant enzyme systems, and selenium: a review. Curr Med Chem. 2007; 14: $1539-1549$.

14 Salonen JT, Alfthan G, Huttunen JK, et al. Association between cardiovascular death and myocardial infarction and serum selenium in a matched-pair longitudinal study. Lancet. 1982; 2: 175-179.

15 Beaglehole R, Jackson R, Watkinson J, et al. Decreased blood selenium and risk of myocardial infarction. Int J Epidemiol. 1990; 19: 918-922.

16 Ponikowski P, Voors AA, Anker SD, et al. 2016 ESC Guidelines for the diagnosis and treatment of acute and chronic heart failure: the Task Force for the diagnosis and treatment of acute and chronic heart failure of the European Society of Cardiology (ESC). Eur J Heart Fail. 2016; 18: 891-975.

17 Chen J. An original discovery: selenium deficiency and Keshan disease (an endemic heart disease). Asia Pac J Clin Nutr. 2012; 21: 320-326.

18 Quercia RA, Korn S, O'Neill D, et al. Selenium deficiency and fatal cardiomyopathy in a patient receiving long-term home parenteral nutrition. Clin Pharm. 1984; 3: 531-535.

19 Boldery R, Fielding G, Rafter T, et al. Nutritional deficiency of selenium secondary to weight loss (bariatric) surgery associated with life-threatening cardiomyopathy. Heart Lung Circ. 2007; 16: 123-126.

20 Twagirumukiza M, Nkeramihigo E, Seminega B, et al. Prevalence of dilated cardiomyopathy in HIV-infected African patients not receiving HAART: a multicenter, observational, prospective, cohort study in Rwanda. Curr HIV Res. 2007; 5: $129-137$.

21 Thygesen K, Alpert JS, Jaffe AS, et al. Third universal definition of myocardial infarction. ESC Committee for Practice Guidelines (CPG). Eur Heart J. 2012; 33: $2551-2567$

22 de Lorgeril M, Salen P, Accominotti M, et al. Dietary and blood antioxidants in patients with chronic heart failure. Insights into the potential importance of selenium in heart failure. Eur J Heart Fail. 2001; 3: 661-669.

23 Koşar F, Sahin I, Taşkapan C, et al. Trace element status (Se, Zn, Cu) in heart failure. Anadolu Kardiyol Derg. 2006; 6: 216-220.

24 Ghaemian A, Salehifar E, Shiraj H, et al. A comparison of selenium concentrations between congestive heart failure patients and healthy volunteers. J Tehran Heart Cent. 2012; 7: 53-57.

25 Oster 0 , Drexler M, Schenk J, et al. The serum selenium concentration of patients with acute myocardial infarction. Ann Clin Res. 1986; 18: 36-42.

26 Hassanzadeh M, Faridhosseini R, Mahini M, et al. Serum levels of TNF-, IL-6, and selenium in patients with acute and chronic coronary artery disease. Iran IImmunol. 2006; 3: 142-145.

27 Bor MV, Cevik C, Uslu I, et al. Selenium levels and glutathione peroxidase activities in patients with acute myocardial infarction. Acta Cardiol. 1999; 54: 271-276.

28 Alexanian I, Parissis J, Farmakis D, et al. Selenium contributes to myocardial injury and cardiac remodeling in heart failure. Int J Cardiol. 2014; 176: 272-273.

29 Kutil B, Ostadal P, Vejvoda J, et al. Alterations in serum selenium levels and their relation to troponin I in acute myocardial infarction. Mol Cell Biochem. 2010; 345:23-27. 30 0ster 0, Prellwitz W, Kasper W, et al. Congestive cardiomyopathy and the selenium content of serum. Clin Chim Acta. 1983; 128: 125-132.

31 Oster 0, Dahm M, Oelert H. Element concentrations (selenium, copper, zinc, iron, magnesium, potassium, phosphorous) in heart tissue of patients with coronary heart disease correlated with physiological parameters of the heart. Eur Heart J. 1993; 14: 770-774.

32 Oster 0, Prellwitz W, Kasper W, et al. Congestive cardiomyopathy and the selenium content of serum. Clin Chim Acta. 1983; 128: 125-132.

33 Witte KK, Nikitin NP, Parker AC, et al. The effect of micronutrient supplementation on quality-of-life and left ventricular function in elderly patients with chronic heart failure. Eur Heart J. 2005; 26: 2238-2244.

34 Alehagen U, Johansson $\mathrm{P}$, Björnstedt $\mathrm{M}$, et al. Cardiovascular mortality and $\mathrm{N}$-terminal-proBNP reduced after combined selenium and coenzyme
Q10 supplementation: a 5-year prospective randomized double-blind placebo-controlled trial among elderly Swedish citizens. Int J Cardiol. 2013; 167: 1860-1866.

35 Raygan F, Behnejad M, Ostadmohammadi V, et al. Selenium supplementation lowers insulin resistance and markers of cardio-metabolic risk in patients with congestive heart failure: a randomised, double-blind, placebo-controlled trial. Br J Nutr. 2018; 120: 33-40.

36 Friberg L, Werner S, Eggertsen G, et al. Rapid down-regulation of thyroid hormones in acute myocardial infarction: is it cardioprotective in patients with angina? Arch Intern Med. 2002; 162: 1388-1394.

37 Iervasi G, Pingitore A, Landi $P$, et al. Low-T3 syndrome: a strong prognostic predictor of death in patients with heart disease. Circulation 2003; 11; 107: 708-713.

38 Kozdag G, Ural D, Vural A, et al. Relation between free triiodothyronine/free thyroxine ratio, echocardiographic parameters and mortality in dilated cardiomyopathy. Eur J Heart Fail. 2005; 7: 113-118.

39 Lima LF, Barbosa $F$ Júnior, et al. Heart failure, micronutrient profile, and its connection with thyroid dysfunction and nutritional status. Clin Nutr. 2019; 38: 800-805 